\title{
Young Children's Risk-Taking: Mothers' Authoritarian Parenting Predicts Risk-Taking by Daughters but Not Sons
}

\author{
Erin E. Wood and Shelia M. Kennison \\ Department of Psychology, Oklahoma State University, 116 North Murray Hall, Stillwater, OK 74078, USA \\ Correspondence should be addressed to Shelia M. Kennison; shelia.kennison@okstate.edu
}

Received 3 June 2017; Revised 19 August 2017; Accepted 12 September 2017; Published 15 October 2017

Academic Editor: Elena Nicoladis

Copyright ( 2017 Erin E. Wood and Shelia M. Kennison. This is an open access article distributed under the Creative Commons Attribution License, which permits unrestricted use, distribution, and reproduction in any medium, provided the original work is properly cited.

\begin{abstract}
We investigated how mothers' parenting behaviors and personal characteristics were related to risk-taking by young children. We tested contrasting predictions from evolutionary and social role theories with the former predicting higher risk-taking by boys compared to girls and the latter predicting that mothers would influence children's gender role development with risk-taking occurring more in children parented with higher levels of harshness (i.e., authoritarian parenting style). In our study, mothers reported their own gender roles and parenting styles as well as their children's risk-taking and activities related to gender roles. The results were only partially consistent with the two theories, as the amount of risk-taking by sons and daughters did not differ significantly and risk-taking by daughters, but not sons, was positively related to mothers' use of the authoritarian parenting style and the girls' engagement in masculine activities. Risk-taking by sons was not predicted by any combination of motherrelated variables. Overall, mothers who were higher in femininity used more authoritative and less authoritarian parenting styles. Theoretical implications as well as implications for predicting and reducing children's risk-taking are discussed.
\end{abstract}

\section{Introduction}

Risk-taking by young children can lead to unintentional injury and, in some cases, hospitalization, permanent disability, and death [1-6]. Efforts to reduce risk-taking in young children through educational interventions with parents and other caregivers are best served by having a complete understanding of the factors predicting children's risk-taking behaviors. Prior research indicates that boys typically engage in more physical risk-taking than girls and are at higher risk of injury and death than girls [1, 2, 7-9]. On the one hand, evolutionary theory explains this sex difference in risk-taking as resulting from differences in biology related to different evolutionary histories for men and women [10, 11]. In contrast, social role theory argues that different socialization experiences of boys and girls in early childhood lead to their developing different gender roles [12-14]. It is important to note that biology and social environment are often correlated and that distinct effects of biology and social environment are possible. In the present research, we investigated the extent to which mothers' behaviors and personal characteristics predict risk-taking by young children.

Theoretical perspectives on young children's risk-taking can be viewed as reflecting the nature-nurture dichotomy. Advocates of the evolutionary perspective emphasize the role of nature in sex differences in children's risk-taking, arguing that they are the result of different evolutionary histories of the men and women [10,11]. Throughout human history, boys and men have typically interacted with samesex social groups that are organized hierarchically in terms of dominance and have engaged in one-on-one and group-ongroup competitiveness that involves risk-taking behaviors. In contrast, in human history, girls and women are believed to have developed primarily dyad relationships involving high levels of emotional support, sharing of problems, and problem solving. In a cross-cultural examination of how boys and girls are trained, Low [15] argued that generally boys were trained to be aggressive and independent, but girls were trained to be obedient and industrious with the training that parents provide to children varying as a function of 
the type of society. In societies in which women access to more resources, girls receive less training to be obedient. Interestingly, Apicella et al. [16] investigated risk-taking with a modern hunter-gather society using an economic game task and found that boys and men took more risks than girls and women in all age groups with the sex difference in risk-taking increasing with age. These results suggest that the greater risktaking by boys and men occurs across cultures and is likely to reflect different evolutionary histories for men and women in human history.

Within the framework of evolutionary psychology, parent-child interactions early in life have been recognized as a critical predictor of children's behaviors during childhood as well as throughout the lifespan $[17,18]$. Children who experience more negative relationships with parents in early life and less parental investment are likely to differ from other children. Studies have shown that girls with higher levels of negative parent-child relationships enter puberty earlier [19], engage in more sexual risk-taking [20], adopt short-term rather than long-term mating strategies [21], and give birth to children earlier in life [20] than girls from other types of family environments. Girls who experience positive relationships with parents during early childhood enter puberty later, take fewer sexual risks, and have children later in life [22, 23]. Longitudinal studies in which children's salivary cortisol was assessed as an indicator of stress showed that adverse home environments were related to abnormal cortisol profiles [2427]. Abnormal cortisol levels were observed for both girls and boys reared in homes with higher levels of instability.

An alternative approach to sex differences in risk-taking and other variables is social role theory, whose proponents argue that sex differences in behavior, which appear to be the result of fixed biological differences between the sexes, instead may be the result of different socialization or nurture experiences [12-14]. Different socialization experiences are also viewed as the primary cause of the development of different gender roles in boys and girls. There is ample evidence that parents' gender roles and parenting behaviors contribute to the family context and together influence children's gender roles and other personal characteristics [28-31]. In terms of gender roles, mothers are expected to show more warmth, nurturing, and active involvement, which is associated with high levels of femininity [30, 32, 33], and expectations for fathers include less involvement in the lives of children than mothers, more dominance, and more aggression than mothers [34], which are characteristics associated with masculinity [33].

With regard to risk-taking, prior research has shown that differences in how parents interact with sons and daughters are related to children's risk-taking $[9,35,36]$. Research by Little and Wyver [37] showed that parents tend to view physical risk-taking more positively in boys than girls and viewed it as being an unmalleable part of being a boy (see also [3]). They also found that parents tended to view girls' physical risk-taking as not integral to being a girl and, therefore, malleable (see also [3]). Other researchers have reported that parents interactions with boys and girls regarding risk-taking also differ, with parents instructing girls to refrain from all physical risk-taking and providing guidance for boys regarding how to avoid injury while taking physical risks $[8,38]$. Another aspect of the family context that has been found to predict children's risk-taking is family income; specifically children from lower income homes have been found to take more risks than other children ([31, 39, 40]; Olsen, Bottorff, and Frankish, 2008).

The purpose of the present research was to investigate the extent to which mothers' personal characteristics and behaviors, specifically mothers' gender roles and parenting styles, were related to risk-taking by children between the ages of two years and five years. We chose to focus on mothers because prior research has shown that mothers are likely to spend more time with children [32] and that mothers' parenting beliefs and behaviors predict fathers' parenting behaviors [41]. Our choice to examine this age range of children stems from the fact that gender-specific behaviors have been shown to emerge by the age of two years and become well established by the age of six years $[9,35]$. Relatively few studies have investigated the relationships between mothers' gender roles, mothers' parenting behaviors, and their children's risk-taking behaviors. In a study conducted in France, Granié [9] investigated the relationship between mothers' gender roles and risk-taking in a sample composed of mostly mothers (i.e., $90 \%$ of the sample). The results showed that parents' gender nonconformity (i.e., higher masculinity in mothers) was related to higher levels of children's gender nonconformity (i.e., higher masculinity in girls and higher femininity in boys) and higher levels of physical risk-taking in sons and daughters.

In the present research, we reasoned that mothers' gender roles, specifically the level of femininity/masculinity, would be related to their parenting styles and that each of these mother variables may be related to children's risk-taking. For example, mothers higher in femininity may be less likely to use the authoritarian parenting style, which includes physical coercion, punishment without explanation or reasoning, and verbal hostility [42-46]. Authoritarian parents are less likely to permit children to have input on rules and are more likely to use corporal punishment and/or verbal abuse when children disobey (Smetana, 1995; [43]). In contrast, both the authoritative and permissive parenting styles involve providing warmth and support to children and encouraging children to have input on family decisions [31, 42-44]. The authoritative parenting style, unlike the permissive parenting style, involves clear rules for children to follow (Smetana, 1995 [43]). Recent research has shown that college students who perceived their parent to have used more authoritative parenting styles during their childhoods described themselves as more feminine and also indicated that they would prefer to use the authoritative parenting style in the future [30]. Similarly, Kelly and Worell [47] found that femininity in men was related to higher levels of warmth experienced from parents during childhood.

In this paper, we report a study in which mothers of young children between the ages of two years and five years completed questionnaires in which they were asked to report their personal characteristics (e.g., gender roles) and behaviors (i.e., parenting styles) as well as the characteristics of their child (i.e., gender-related activities) and their child's 
behavior (i.e., risk-taking). We tested the contrasting predictions of evolutionary and social role theories. In accordance with evolutionary theory, we expected to observe higher levels of risk-taking for boys than for girls. Both theoretical perspectives predict that children will take more risks if they are raised in homes with parenting styles involving more harshness and less warmth (i.e., authoritarian parenting style), which may occur more often with mothers who are more masculine/less feminine. In accordance with social role theory, we expected to find this relationship for both boys and girls.

\section{Method}

2.1. Participants. Ninety-three mothers participated in the study. Their mean age was 34.29 years $(\mathrm{SD}=4.79)$. In the sample, $95.7 \%$ of participants were married; $1.1 \%$, divorced; $2.2 \%$, single and cohabiting with a partner; and $1.1 \%$, single and in a relationship with a partner who did not live in the home. In terms of ethnicity, $90.3 \%$ of the sample was Caucasian; 2.2\%, Hispanic; 3.2\%, Asian; and 3.2\%, Native American; and $1.1 \%$ belonged to more than one category. In terms of education level, $1.1 \%$ had completed high school or had a GED, 9.7\% had some college experience, $6.5 \%$ had completed a 2 -year college degree, $34 \%$ had completed a 4 -year college degree, $32.3 \%$ had completed a master's degree, $1.1 \%$ had completed a professional degree, and $14 \%$ had completed a doctoral degree. In the sample, 53.8\% of mothers described characteristics and behaviors of a daughter and $46.2 \%$ of a son. Only $1.1 \%$ of the sample involved a nonbiological mother-child relationship. The average age of daughters was 3.70 years ( $\mathrm{SD}=1.04)$, and the average age of sons was 3.28 years $(\mathrm{SD}=1.05)$. In terms of birth order, $22.6 \%$ of children were only children, $34.4 \%$ of children were first born, $8.6 \%$ were middle-born, and $32.3 \%$ were lastborn children. In terms of family income, $6.5 \%$ earned less than $\$ 30,000$ annually; $18.3 \%$ earned between $\$ 30,000$ and $\$ 59,999$ annually; $4.3 \%$ earned between $\$ 60,000$ and $\$ 69,999$ annually; $36.6 \%$ earned between $\$ 70,000$ and $\$ 99,999$ annually; and $38.7 \%$ earned $\$ 100,000$ or more annually. Mothers reported spending 4.63 hours per day with their child (SD = 3.05). Mothers were asked about whom they relied on most for secondary childcare: $41.9 \%$ reported that they relied on their spouse, $8.6 \%$ on grandparents; $3.2 \%$ on other family members, $1.1 \%$ on friends; $3.2 \%$ on paid baby sitters; $16.1 \%$ on childcare centers, and $25.8 \%$ on a combination of individuals or groups.

2.2. Materials. We assessed mothers' gender roles, parenting styles, their child's gender roles, and their child's risk-taking behaviors. We assessed mothers' gender roles using the 60item Bem Sex Roles Inventory (BSRI) [33]. Mothers were asked to define how descriptive certain personality attributes applied to them on a 7 -point scale $(1=$ never, $7=$ always $)$. Of these attributes, 20 were defined as masculine (i.e., having leadership abilities and ambitious); 20 were used to define femininity (i.e., warm and gentle), and 20 were defined as androgynous (i.e., adaptable and shy). For the three categories, scores were summed across the 20 items. The average femininity score for mothers was $5.00(\mathrm{SD}=0.71)$. The average masculinity score for mothers was 5.09 (SD = $0.71)$. The average androgyny score for mothers was 4.39 $(\mathrm{SD}=0.41)$. In the present research, we observed internal consistency for the three subscales, as reflected in Cronbach's alphas: masculinity $(\alpha=.89)$, femininity $(\alpha=.88)$, and androgyny $(\alpha=.54)$.

Mothers' Parenting Styles. We assessed parenting style using the 32-item version of the Parenting Styles and Dimensions Questionnaire (PSDQ) [46], which distinguishes three types of parenting style: authoritative, authoritarian, and permissive. Fifteen questions were designed to measure one's use of the authoritative parenting style; 12 questions the authoritarian parenting styles; and 5 questions the permissive parenting styles. Respondents responded to questions on a 5-point scale $(1=$ never, $5=$ always $)$. Responses were averaged for each type of parenting style with higher numbers reflecting that the parent frequently engaged in the parenting style. Average score of authoritativeness for mothers in this study was 60.26 $(\mathrm{SD}=6.68)$, authoritarianism was $21.043(\mathrm{SD}=5.31)$, and permissiveness was $10.19(\mathrm{SD}=2.96)$. In the present research, the following Cronbach's alphas were observed: authoritative parenting $(\alpha=.70)$, authoritarian parenting $(\alpha=.80)$, and permissive parenting $(\alpha=.70)$.

Child's Gender Roles. We assessed children's gender roles in terms of their conformity to gender-specific behavior using the 24-item version of the Preschool Activities Inventory (PSAI) [48]. The PSAI asks about the child's typical activities, including the types of toys involved in play activities. There are 12 masculine items included in the inventory (e.g., guns and cars) and 12 feminine items (e.g., dolls and tea set). Each item is accompanied by a 5 -point scale $(0=$ never; $4=$ very often). Following Golombok and Rust [48], the PSAI score for the child was calculated using the following formula: PSAI = $48.25+1.1$ (sum of male items - sum of female items). PSAI scores above the median are considered masculine and scores below the median are considered feminine. For this study, the average score for males was $65.70(\mathrm{SD}=8.70)$ and the average score for daughters was $37.69(\mathrm{SD}=12.04)$. In the present research, the following reliabilities were observed: masculine items $(\alpha=.82)$ and feminine items $(\alpha=.89)$.

Child Risk-Taking. We assessed children's risk-taking using the 24-item Injury Behavior Checklist (IBC) [49]. Sample items include plays with fire and runs out into the street. Each item was accompanied by a 5 -point scale $(1=$ not at all, $5=$ very often/more than once a week). The child's IBC score was the sum of the scores across all items. Higher scores indicated that the child spent more time participating in activities that could lead to injury. For this study, the average score for sons was $52.56(\mathrm{SD}=9.68)$ and the average score for daughters was $51.54(\mathrm{SD}=11.47)$. In the present research, we observed high reliability for the scale $(\alpha=.88)$.

2.3. Procedure. After obtaining IRB approval, we utilized a snowball sampling method, recruiting mothers in person, with printed flyers at community childcare facilities, and with announcements disseminated through multiple electronic 
social media sites. All participants completed the measures in the same order: BSRI, PSAI, IBC, PSDQ, and demographics. Mothers reported child variables for just one child. The demographics questionnaire included participant information pertaining to age, sex, and intentional interaction (i.e., number of hours in which parent is actively engaging with the child per day). At the end of the survey, all participants were invited to enter themselves into a lottery drawing for $\$ 50$.

\section{Results}

We calculated the key variables from mothers' responses. These included child risk-taking (i.e., score on the IBC), children's gender role (i.e., score on the PSAI), mothers' gender roles (i.e., femininity, masculinity, and androgyny), mothers' parenting styles (authoritative, authoritarian, and permissive), children's age, and family income. Table 1 provides a summary of the descriptive statistics for the key variables by sex of the child. Inspection of the variances indicated that the variances for variables may have differed for sons and daughters. We assessed the equality of variances for sons' and daughters' scores [50]. We found that the only significant result was for IBC scores. The variances for sons' and daughters' IBC scores were not equal, $F(1,91)=6.45$, $p=.013$. A Mann-Whitney test indicated that IBC scores did not differ significantly for sons $(\mathrm{Mdn}=52.00)$ and daughters $(\mathrm{Mdn}=48.50), U=948, p=.42$. Comparisons for other variables revealed that sons were described as engaging in significantly higher numbers of masculine activities than were daughters, as reflected in higher scores on the PSAI, $t(91)=12.67, p=.000, d=2.67$. For other variables, sons and daughter did not differ significantly: (a) age, $t(91)=$ 1.94, $p=.06$; (b) mothers' levels of femininity, masculinity, and androgyny, ts < 1.70, ps > .09; (c) mothers' levels of authoritarian, authoritative, or permissive parenting styles, ts < 1.14, ps > .26; and (e) family income, $t$ s < 1.14, ps > .53.

We examined the interrelationships among the key variables for sons and daughters in a series of Pearson productmoment correlations. Table 2 displays the summary of correlational results by sex of the child. The results showed that, for both girls and boys, mothers who were higher in femininity used the authoritarian parenting style less frequently (overall $r=-.35, p=.001$ ) and used the authoritative parenting style more frequently (overall $r=.42, p<.001$ ) than others. For sons, but not daughters, age was related to risk-taking, as older sons took more risks than younger sons. Sons whose mothers reported more frequent use of the authoritative parenting style engaged in more masculine behaviors (as assessed by the PSAI) than others sons. For daughters, but not sons, higher levels of risk-taking were reported for daughters who generally engaged in more masculine behaviors (as assessed by the PSAI) and whose mothers reported using the authoritarian parenting style more often.

In order to investigate further the factors that predict risktaking in sons and daughters, we carried out separate multiple regression analyses in which IBC scores were the dependent variable and authoritarian parenting and PSAI scores were the independent variables. In both analyses, independent variables were entered simultaneously. Table 3 displays a summary of the variables, standard errors, beta values, standardized betas, and $R^{2}$ from these analyses. For girls, the model was significant, $F(2,49)=11.74, p<.001$ accounted for $31 \%$ of the variance in risk-taking (adjusted $R^{2}=$ .31). The results showed that both variables were significant predictors: (a) children's gender role (as measured by the PSAI) with greater participation in masculine activities related to more risk-taking $(\beta=.40, p=.002)$ and $(\mathrm{b})$ mothers' authoritarian parenting style with more frequent use of the authoritarian parenting style related to more risk-taking ( $\beta=.34, p=.007)$. We confirmed that the variables met collinearity assumptions (VIFs $=.96$ and Tolerance values $=1.05)$. For boys, the model was not significant, $F(2,42)=$ $.48, p=.62$. In order to explore whether boys' risk-taking was predicted by other combinations of variables (e.g., authoritative parenting style and mothers' femininity), additional multiple regressions models were tested, but none were significant.

\section{Discussion}

The present research investigated the relationships among mothers' gender roles, their parenting styles, and their children's gender roles and risk-taking behavior. The results showed that, for girls, risk-taking was predicted by the mothers' use of the authoritarian parenting style and girls' gender roles (as measured by the PSAI). The amount of risktaking observed for boys and girls did not differ significantly; however, the variance observed in risk-taking scores for girls and boys differed, as the amount of risk-taking varied more among girls than among boys. For boys, risk-taking was not significantly related to any variable or predicted by various combinations of variables. Correlational analyses showed that for both girls and boys greater femininity in mothers was significantly related to mothers using more authoritative parenting behaviors and fewer authoritarian parenting behaviors. For boys, but not girls, we found that mothers' use of more authoritative parenting behaviors was significantly related to more masculine behaviors in boys.

With regard to the theoretical perspectives discussed earlier, the results are partially consistent with each. In accordance with social role theory, we expected to find that mother variables would predict risk-taking by both girls and boys. However, the present results showed that mothers' use of the authoritarian parenting style predicted risk-taking in girls only, while the amount of authoritarian parenting reported by mothers did not differ significantly for girls and boys. In accordance with evolutionary theory, we expected to find more risk-taking by boys than girls, but the results showed that there was no significant difference in boys' and girls' risk-taking. Both the ranges and standard deviations of boys' and girls' risk-taking were similar to the data from the sample for girls having slightly higher variance.

The present study had multiple limitations. Foremost, the present research relied on mothers to report children's behavior, as has many other prior studies investigating child behavior. Parents rely on memory to provide estimates of how often their child engaged in various behaviors; thus, 


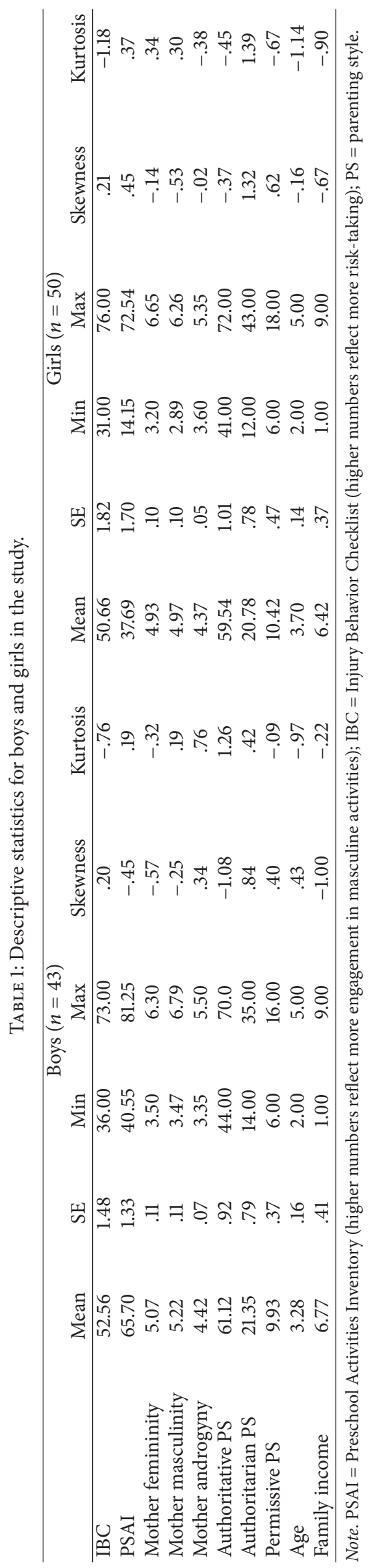


TABLE 2: Summary of correlational analyses for boys and girls.

\begin{tabular}{|c|c|c|c|c|c|c|c|c|c|c|}
\hline & $(1)$ & (2) & (3) & (4) & (5) & (6) & (7) & $(8)$ & (9) & $(10)$ \\
\hline (1) IBC & - & $.47^{* * *}$ & -.27 & .12 & -.10 & .01 & $.43^{* *}$ & .18 & -.03 & -.03 \\
\hline (2) PSAI & .15 & - & .02 & .13 & -.10 & .12 & .21 & .18 & -.13 & .03 \\
\hline (3) Mother femininity & .21 & .15 & - & -.07 & $.56^{* * *}$ & $.46^{* *}$ & $-.37^{* *}$ & -.19 & .06 & $-.29^{*}$ \\
\hline (4) Mother masculinity & -.10 & .14 & -.12 & - & .12 & .13 & -.02 & -.20 & .01 & .07 \\
\hline (5) Mother androgyny & .25 & .15 & $.53^{* * *}$ & .20 & - & .25 & -.23 & -.06 & .13 & -.17 \\
\hline (6) Authoritative PS & .21 & .14 & $.34^{*}$ & .05 & .13 & - & -.25 & -.11 & .02 & -.05 \\
\hline (7) Authoritarian PS & -.01 & $.41^{* *}$ & $-.34^{*}$ & .28 & -.01 & -.16 & - & $.52^{* * *}$ & .03 & .04 \\
\hline (8) Permissive PS & -.06 & -.07 & -.01 & $.40^{*}$ & $.45^{* *}$ & -.02 & $.36^{*}$ & - & -.07 & .03 \\
\hline (9) Age & -.11 & $.41^{* *}$ & -.06 & .01 & .10 & .24 & -.17 & -.07 & - & .21 \\
\hline (10) Family income & .02 & .03 & -.27 & .11 & .12 & -.17 & .22 & .20 & .25 & - \\
\hline
\end{tabular}

Note. Lower half of the matrix displays correlations for boys and the upper half, for girls. PSAI = Preschool Activities Inventory (higher numbers reflect more engagement in masculine activities by children); IBC = Injury Behavior Checklist (higher numbers reflect more risk-taking); ${ }^{*} p<.05,{ }^{* *} p<.01$, and ${ }^{* * *} p<$ .001 .

TABLE 3: Summary of multiple regression results with authoritarian parenting style and children's PSAI predicting risk-taking for girls and boys.

\begin{tabular}{|c|c|c|c|c|c|c|}
\hline \multirow[b]{2}{*}{ Predictors } & \multicolumn{3}{|c|}{ Girls } & \multicolumn{3}{|c|}{ Boys } \\
\hline & $B$ & SE & $\beta$ & $B$ & SE & $\beta$ \\
\hline Intercept & 18.00 & 7.02 & - & 45.15 & 12.61 & - \\
\hline Authoritarian parenting style & .80 & .29 & $.34^{* *}$ & -.04 & .30 & -.02 \\
\hline PSAI & .43 & .13 & $.40^{* *}$ & .17 & .16 & .15 \\
\hline Adjusted $R^{2}$ & & .31 & & & 0.03 & \\
\hline
\end{tabular}

Note. PSAI $=$ Preschool Activities Inventory (higher numbers reflect more engagement in masculine activities by children); ${ }^{* *} p<.01$.

estimates can be unreliable. In addition, mothers' responses may have been influenced by social desirability bias, as behaviors perceived as socially undesirable may have been underreported. It is possible that the failure to observe an overall difference in risk-taking by boys and girls was due, as least in part, to the IBC's [49] scale, which had only 5-points $(1=$ not at all, $5=$ very often/more than once a week $)$. The scale is unable to distinguish between risk-taking that occurs more than once a week from that occurring multiple times a week from that occurring multiple times a day. A final limitation is the fact that majority of mothers in our sample were married, relatively well-educated, and relatively high family income, as the results may not necessarily generalize to other types of populations.

Future research is needed to determine whether the present results will generalize to other types of populations, such as lower income families as well as families headed by single parents. To the extent that it is possible, it would be ideal to obtain objective measures of children's behaviors in addition to parent report measures. In the event that future studies replicate the relationship that was found between the use of the authoritarian style and risk-taking by girls, educational programs could be developed to raise awareness among parents about the relationship between authoritarian parenting and risk-taking in girls. The effectiveness of such programs in reducing children's risk-taking would require empirical confirmation. Lastly, future research should examine how individual differences in children's personality are related to parenting style and how both relate to children's risk-taking. Although there is a tendency to view the relationship between parenting and the behavior of children as unidirectional with parenting influencing behavior, it is important to stress that, at least in some cases, the relationship may be bidirectional. Parents may adopt different, harsher parenting behaviors for children perceived as particularly difficult. The results of the present study may reflect the fact that when daughters engage in risk-taking, mothers may increase their use of authoritarian parenting strategies more so than they do when sons engage in risk-taking, because risk-taking by girls is viewed as more problematic than risk-taking by sons.

In summary, the present study provided evidence that there are relationships among mothers' gender roles and parenting styles. Further, the use of the authoritarian parenting style predicted risk-taking for young girls, but not boys. We hope the results provide an impetus for future research that investigates risk-taking in children with the long-term aim of reducing it and the injuries in children that can occur. We believe that, by finding a way to reduce forms of physical risktaking, we not only will be reducing the child injury or death rates, but also will help alleviate or prevent the emotional or stress experienced by all family members when a child is injured.

\section{Conflicts of Interest}

The authors declare that there are no conflicts of interest regarding the publication of this article. 


\section{References}

[1] H. J. Ginsburg and S. M. Miller, "Sex differences in childrens risk-taking behavior," Child Development, vol. 53, no. 2, pp. 426$428,1982$.

[2] M.-A. Granié, "Effects of gender, sex-stereotype conformity, age and internalization on risk-taking among adolescent pedestrians," Safety Science, vol. 47, no. 9, pp. 1277-1283, 2009.

[3] B. A. Morrongiello, D. Zdzieborski, and J. Normand, "Understanding gender differences in children's risk taking and injury: A comparison of mothers' and fathers' reactions to sons and daughters misbehaving in ways that lead to injury," Journal of Applied Developmental Psychology, vol. 31, no. 4, pp. 322-329, 2010.

[4] K. M. Galligan and J. E. Kuebli, "Preschoolers' perceptions of their mothers' and fathers' reactions to injury-risk behavior," Accident Analysis \& Prevention, vol. 43, no. 4, pp. 1316-1322, 2011.

[5] M. Wells, B. A. Morrongiello, and A. Kane, "Unintentional injury risk in school-age children: Examining interrelations between parent and child factors," Journal of Applied Developmental Psychology, vol. 33, no. 4, pp. 189-196, 2012.

[6] J. Ablewhite, D. Kendrick, M. Watson, and I. Shaw, "Maternal perceptions of supervision in pre-school-aged children: a qualitative approach to understanding differences between families living in affluent and disadvantaged areas," Primary Health Care Research \& Development, vol. 16, no. 4, pp. 346-355, 2015.

[7] J. Byrd-Craven and D. C. Geary, "Biological and evolutionary contributions to developmental sex differences," Reproductive BioMedicine Online, vol. 15, no. 2, article no. 2853, pp. 12-22, 2007.

[8] B. A. Morrongiello and T. Dawber, "Parental Influences on Toddlers' Injury-Risk Behaviors: Are Sons and Daughters Socialized Differently?" Journal of Applied Developmental Psychology, vol. 20, no. 2, pp. 227-251, 1999.

[9] M.-A. Granié, "Gender stereotype conformity and age as determinants of preschoolers' injury-risk behaviors," Accident Analysis \& Prevention, vol. 42, no. 2, pp. 726-733, 2010.

[10] D. C. Geary, Male, Female: The Evolution of Human Sex Differences, American Psychological Association, Washington, DC, USA, 2nd edition, 2010.

[11] D. C. Geary, J. Byrd-Craven, M. K. Hoard, J. Vigil, and C. Numtee, "Evolution and development of boys' social behavior," Developmental Review, vol. 23, no. 4, pp. 444-470, 2003.

[12] A. H. Eagly, Sex Differences in Social Behavior: A Social-Role Interpretation, Erlbaum, N. J., Hillsdale, Mich, USA, 1987.

[13] A. H. Eagly, "Sex differences in social behavior: Comparing social role theory and evolutionary psychology," American Psychologist, vol. 52, no. 12, pp. 1380-1383, 1997.

[14] A. H. Eagly and W. Wood, "Explaining sex differences in social behavior: a meta- analytic perspective," Personality and Social Psychology Bulletin, vol. 17, pp. 306-315, 1991.

[15] B. S. Low, "Cross-cultural patterns in the training of children: an evolutionary perspective," Journal of Comparative Psychology, vol. 103, no. 4, pp. 311-319, 1989.

[16] C. L. Apicella, A. N. Crittenden, and V. A. Tobolsky, "Huntergatherer males are more risk-seeking than females, even in late childhood," Evolution and Human Behavior, vol. 38, no. 5, pp. 592-603, 2017.

[17] J. Belsky, R. M. Houts, and R. M. P. Fearon, "Infant attachment security and the timing of puberty: testing an evolutionary hypothesis," Psychological Science, vol. 21, no. 9, pp. 1195-1201, 2010.

[18] J. Belsky, J. Sligo, S. R. Jaffee, L. Woodward, and P. A. Silva, "Intergenerational transmission of warm-sensitive-stimulating parenting: a prospective study of mothers and fathers of 3-yearolds," Child Development, vol. 76, no. 2, pp. 384-396, 2005.

[19] J. Belsky, L. Steinberg, and P. Draper, "Childhood experience, interpersonal development, and reproductive strategy: and evolutionary theory of socialization," Child Development, vol. 62, no. 4, pp. 647-670, 1991.

[20] C. E. Garver-Apgar, S. W. Gangestad, and J. A. Simpson, "Women's perceptions of men's sexual coerciveness change across the menstrual cycle," Acta Psychologica Sinica, vol. 39, no. 3, pp. 469-480, 2007.

[21] B. J. Ellis, G. L. Scholmer, E. H. Tilley, and E. A. Butler, "Impact of fathers on risky sexual behavior in daughter: A genetically and environmentally controlled sibling study," Development and Psychopathology, vol. 24, Article ID S095457941100085, pp. 317332, 2012.

[22] B. J. Ellis, "Timing of pubertal maturation in girls: An integrated life history approach," Psychological Bulletin, vol. 130, no. 6, pp. 920-958, 2004.

[23] B. J. Ellis and D. F. Bjorklund, "Beyond mental health: An evolutionary analysis of development under risky and supportive environmental conditions: An introduction to the special issue," Developmental Psychology, vol. 48, pp. 591-597, 2012.

[24] M. V. Flinn, "Family environment, stress, and health during childhood," in Hormones, Health, and Behavior, C. Panter-Brick and C. Worthman, Eds., pp. 105-138, Cambridge University Press, Cambridge, UK, 1999.

[25] M. V. Flinn and B. England, "Childhood stress and family environment," Current Anthropology, vol. 36, pp. 854-866, 1995.

[26] M. V. Flinn and B. G. England, "Social economics of childhood glucocorticoid stress response and health," American Journal of Physical Anthropology, vol. 102, no. 1, pp. 33-53, 1997.

[27] M. V. Flinn, R. J. Quinlan, M. T. Turner, S. A. Decker, and B. G. England, "Male-female differences in effects of parental absence on glucocorticoid stress response," Human Nature, vol. 7, no. 2, pp. 125-162, 1996.

[28] J. J. Endendijk, M. G. Groeneveld, S. R. van Berkel, E. T. HallersHaalboom, J. Mesman, and M. J. Bakermans-Kranenburg, "Gender stereotypes in the family context: mothers, fathers, and siblings," Sex Roles, vol. 68, no. 9-10, pp. 577-590, 2013.

[29] S. M. McHale, A. C. Crouter, and C. J. Tucker, "Family context and gender role socialization in middle childhood: Comparing girls to boys and sisters to brothers," Child Development, vol. 70, no. 4, pp. 990-1004, 1999.

[30] Y.-C. Lin and R. E. Billingham, "Relationship between parenting styles and gender role identity in college students," Psychological Reports: Relationships \& Communications, vol. 114, no. 1, pp. 250-271, 2014.

[31] D. C. Schwebel and J. Gaines, "Pediatric unintentional injury: Behavioral risk factors and implications for prevention," Journal of Developmental \& Behavioral Pediatrics, vol. 28, no. 3, pp. 245254, 2007.

[32] J. A. Arditti, D. D. Godwin, and J. Scanzoni, "Perceptions of parenting behavior and young women's gender role traits and preferences," Sex Roles, vol. 25, no. 3-4, pp. 195-211, 1991.

[33] S. L. Bem, "The measurement of psychological androgyny," Journal of Consulting and Clinical Psychology, vol. 42, no. 2, pp. 155-162, 1974. 
[34] E. E. Maccoby, "The gender of child and parent as factors in family dynamics," in Children's Influence on Family Dynamics: The Neglected Side of Family Relationships, pp. 191-206, Lawrence Erlbaum Associates, Mahwah, NJ, USA, 2003.

[35] M. W. Clearfield and N. M. Nelson, "Sex differences in mothers' speech and play behavior with 6-, 9-, and 14-month-old infants," Sex Roles, vol. 54, no. 1-2, pp. 127-137, 2006.

[36] L. K. Hagan and J. Kuebli, "Mothers' and fathers' socialization of preschoolers' physical risk taking," Journal of Applied Developmental Psychology, vol. 28, no. 1, pp. 2-14, 2007.

[37] H. Little and S. Wyver, "Individual differences in children's risk perception and appraisals in outdoor play environments," International Journal of Early Years Education, vol. 18, no. 4, pp. 297-313, 2010.

[38] B. A. Morrongiello and K. Hogg, "Mothers' Reactions to Children Misbehaving in Ways that Can Lead to Injury: Implications for Gender Differences in Children's Risk Taking and Injuries," Sex Roles, vol. 50, no. 1-2, pp. 103-118, 2004.

[39] D. S. Mull, P. F. Agran, D. G. Winn, and C. L. Anderson, "Injury in children of low-income Mexican, Mexican American, and non-Hispanic white mothers in the USA: A focused ethnography," Social Science \& Medicine, vol. 52, no. 7, pp. 1081-1091, 2001.

[40] T. G. O’Connor, L. Davies, J. Dunn, J. Golding, and ALSPAC Study team, "Distribution of accidents, injuries, and illnesses by family type," Pediatrics, vol. 106, no. 5, pp. 1-6, 2000.

[41] N. J. Cabrera, J. Fagan, V. Wight, and C. Schadler, "Influence of mother, father, and child risk on parenting and children's cognitive and social behaviors," Child Development, vol. 82, no. 6, pp. 1985-2005, 2011.

[42] P. Braza, R. Carreras, J. M. Muñoz et al., "Negative maternal and paternal parenting styles as predictors of children's behavioral problems: moderating effects of the child's sex," Journal of Child and Family Studies, vol. 24, no. 4, pp. 847-856, 2015.

[43] K. Coolahan, C. McWayne, J. Fantuzzo, and S. Grim, "Validation of a multidimensional assessment of parenting styles for low-income African-American families with preschool children," Early Childhood Research Quarterly, vol. 17, no. 3, pp. 356373, 2002.

[44] M. M. Domenech RodrÍguez, M. R. Donovick, and S. L. Crowley, "Parenting styles in a cultural context: observations of protective parenting in first-generation latinos," Family Process, vol. 48, no. 2, pp. 195-210, 2009.

[45] C. C. Robinson, B. Mandleco, S. F. Olsen, and C. H. Hart, "Authoritative, authoritarian, and permissive parenting practices: Development of a new measure," Psychological Reports, vol. 77, pp. 819-830, 1995.

[46] C. C. Robinson, B. Madleco, S. F. Olsen, and C. H. Hart, "The parenting styles and dimensions questionnaire," in Handbook of Family Measurement Techniques, B. F. Perlmutter, J. Touliatos, and G. W. Holden, Eds., vol. 3, pp. 319-321, Sage, Thousand Oaks, Calif, USA, 2001.

[47] J. A. Kelly and L. Worell, "Parent behaviors related to masculine, feminine, and androgynous sex role orientations," Journal of Consulting and Clinical Psychology, vol. 44, no. 5, pp. 843-851, 1976.

[48] S. Golombok and J. Rust, "The pre-school activities inventory: a standardized assessment of gender role in children," Psychological Assessment, vol. 5, no. 2, pp. 131-136, 1993.

[49] M. L. Speltz, N. Gonzales, S. Sulzbacher, and L. Quan, "Assessment of injury risk in young children: A preliminary study of the injury behavior checklist," Journal of Pediatric Psychology, vol. 15, no. 3, pp. 373-383, 1990.
[50] H. Levene, "Robust tests for equality of variances," in Contributions to Probability and Statistics: Essays in Honor of Harold Hotelling, I. Olkin, S. G. Ghurye, W. Hoeffding, W. G. Madow, H. B. Manns, and H. B. Mann, Eds., pp. 278-292, Stanford University Press, Palo Alto, CA, USA, 1960. 


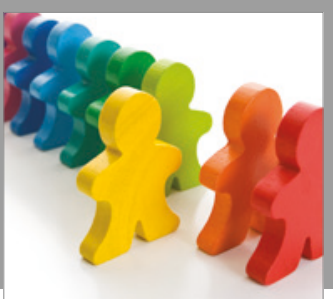

Autism

Research and Treatment
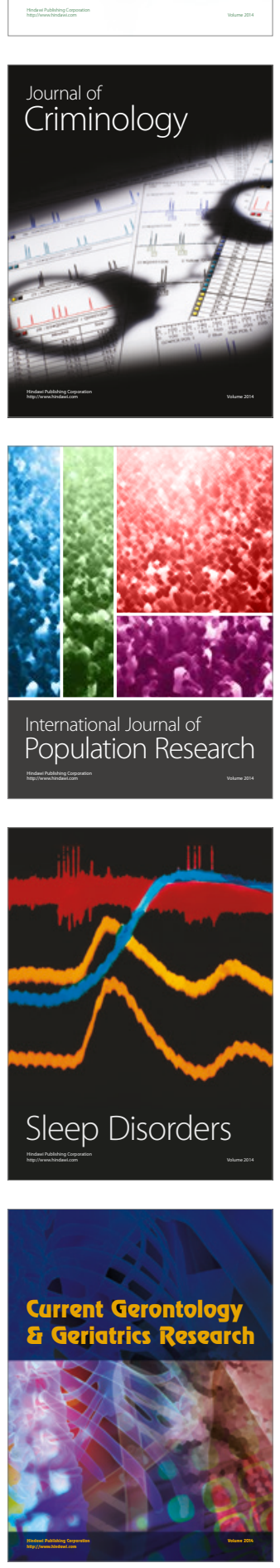

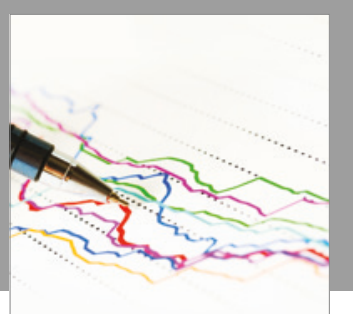

Economics

Research International

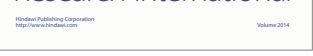

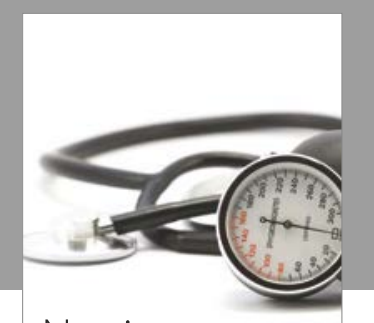

Nursing

Research and Practice

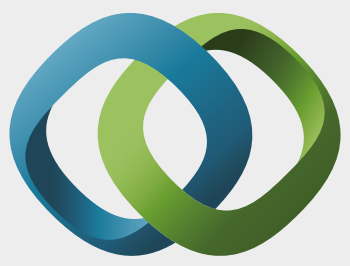

\section{Hindawi}

Submit your manuscripts at

https://www.hindawi.com
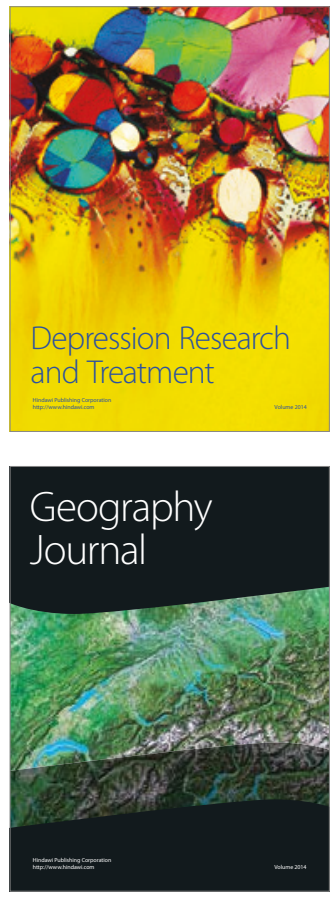
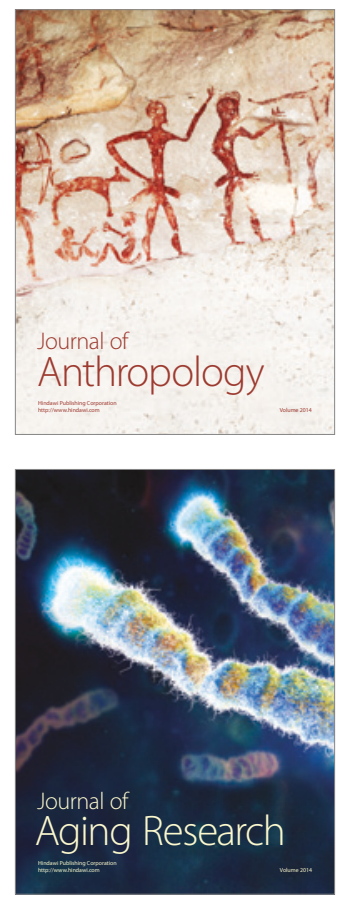
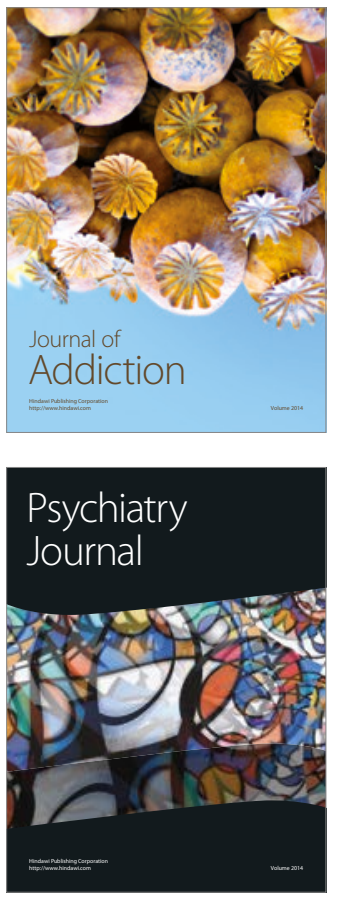

Child Development

Research

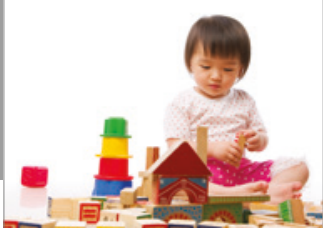

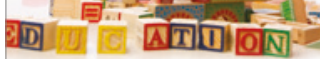
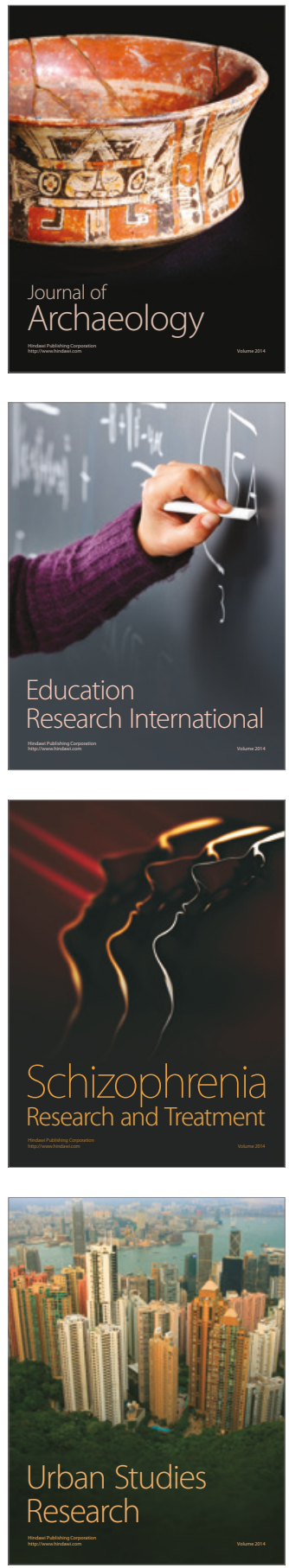